\title{
Correction to: Semi-automated Operational Modal Analysis Methodology to Optimize Modal Parameter Estimation
}

\author{
Eleonora M. Tronci $^{1}$ (D) Maurizio De Angelis ${ }^{1} \cdot$ Raimondo Betti $^{2}$. \\ Vittorio Altomare ${ }^{3}$
}

Published online: 13 July 2020

๑) Springer Science+Business Media, LLC, part of Springer Nature 2020

\section{Correction to: Journal of Optimization Theory and Applications https://doi.org/10.1007/s10957-020-01694-X}

Since the publication of this article [1] we noticed the Greek characters were not published correctly due to a conversion error in production process.

This original article has been corrected.

\section{References}

1. Tronci, E.M., De Angelis, M., Betti, R., et al.: Semi-automated operational modal analysis methodology to optimize modal parameter estimation. J. Optim. Theory Appl. (2020). https://doi.org/10.1007/ s10957-020-01694-x

Publisher's Note Springer Nature remains neutral with regard to jurisdictional claims in published maps and institutional affiliations.

The original article can be found online at https://doi.org/10.1007/s10957-020-01694-x.

$凶 \quad$ Maurizio De Angelis

maurizio.deangelis@uniroma1.it

$凶$ Raimondo Betti

rb68@columbia.edu

$凶$ Vittorio Altomare

vittorio.altomare@uniroma3.it

Eleonora M. Tronci

eleonoram.tronci@uniroma1.it

1 Sapienza University of Rome, Rome, Italy

2 Columbia University, New York, USA

3 Roma Tre University, Rome, Italy 